\title{
Northern Hemisphere sea ice simulations by global climate models
}

\author{
John E. Walsh \& Michael S. Timlin
}

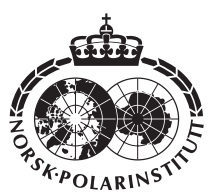

The study described here is a synthesis of global climate model projections of Northern Hemisphere sea ice through the end of the 21st century. The synthesis includes an enhancement of the informational content of the projections from a set of five global atmosphere-ocean-ice models. The adjustments are based on the systematic errors in the models' present-day simulations relative to the HadISST observational data set. All models show decreases of sea ice through the 21st century when forced by the B2 scenario of greenhouse gas and aerosol concentrations. However, the differences in the present-day ice coverage simulated by the models are sufficiently large that they dominate the across-model variances of the projected ice extents. The adjustments based on the present-day biases remove much of the spread among the projections. The decreases of the adjusted ice extent by the year 2100 range from about $12 \%$ to about $46 \%$. The percentage decreases are larger in summer than in winter; much of the Arctic Ocean is ice-free at the time of the summer ice minimum by the year 2099.

J. E. Walsh \& M. S. Timlin, Dept. of Atmospheric Sciences, University of Illinois, 105 South Gregory Avenue, Urbana,IL 61801,USA,walsh@atmos.uiuc.edu.

In assessments of ongoing and projected climate change, sea ice is a critical element. Not only is sea ice an indicator of climate change through its integration of thermodynamic and dynamic forcing of the high-latitude surface, but it is also an agent of climate change through feedbacks involving the coupled atmosphere-ocean-ice system. Global climate models simulate the coupling and, in principle, the feedbacks involving sea ice. Unfortunately, the coarse resolution and simplified parameterizations in these models introduce systematic errors into the simulations of the atmosphere, the ocean and sea ice. These errors can be evaluated in simulations of the present climate by comparing the simulations with observational data. However, the presence of systematic errors presents significant challenges in the use of these models to simulate climate change, since the models are essentially being asked to capture changes from flawed ini- tial states. The Intergovernmental Panel on Climate Change (IPCC 2001) and other assessments of future climate change have devoted considerable attention to the uses of these models for projections of climate change over the next several decades to a century. Effective uses of model projections are especially important in such efforts because models are the most powerful tools available for projecting climate changes. Alternative statistical approaches and analogs to past climate change are highly questionable in the present situation, when anthropogenically driven changes in greenhouse concentrations are occurring at unprecedented rates.

The Arctic Climate Impact Assessment (ACIA, www.acia.uaf.edu/) is an international effort, coordinated by the International Arctic Science Council, to evaluate ongoing and projected changes in the Arctic climate system. Changes in sea ice are of major importance in ACIA, not 


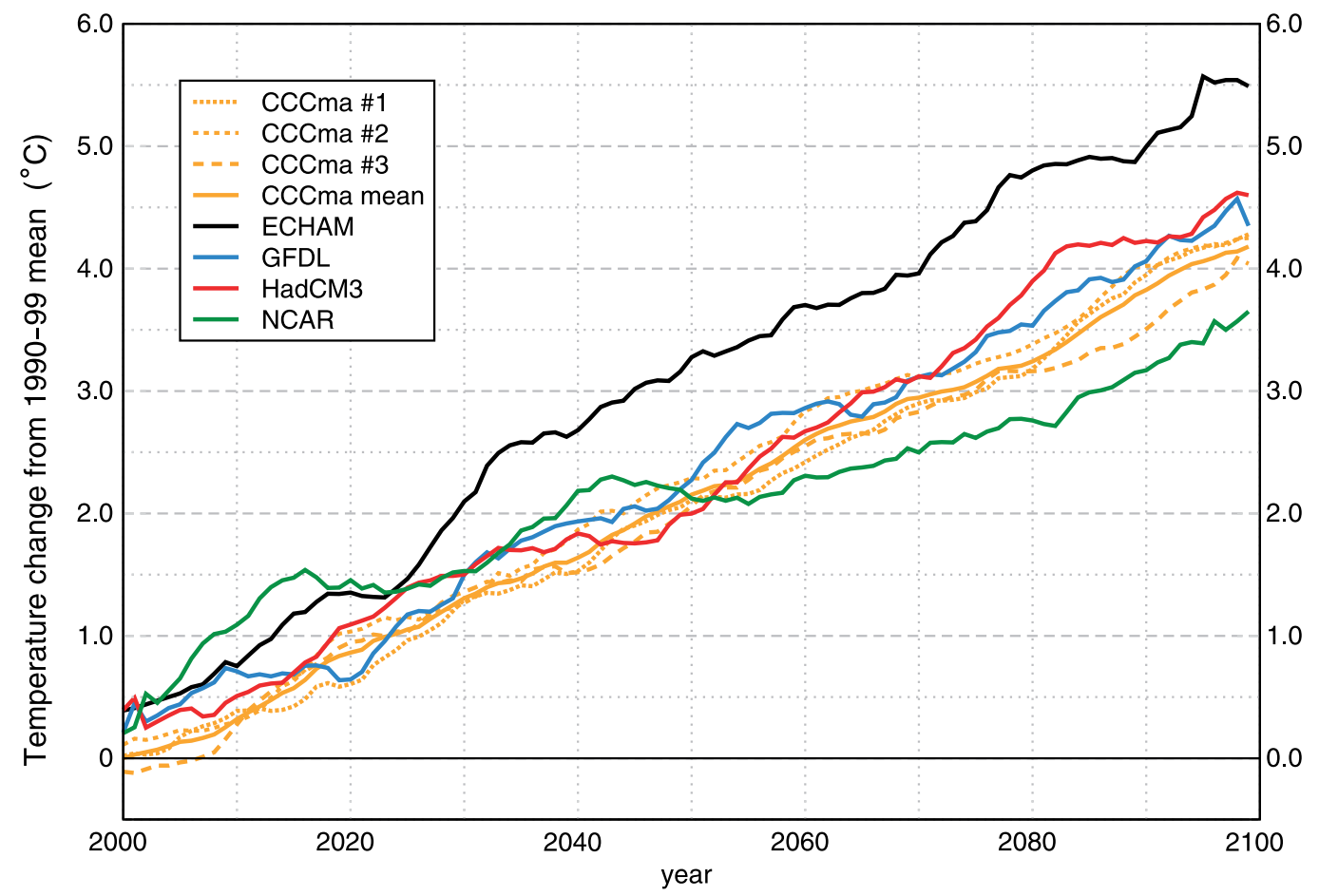

Fig. 1. Projected changes of Arctic surface air temperature $\left({ }^{\circ} \mathrm{C}\right)$, averaged over $60-90^{\circ} \mathrm{N}$, from five global climate models identified in the legend (see Box 1). Changes are relative to each model's mean value for 1990-99 and are plotted as 11-year running means centred on indicated year. Results from CCCma model are shown for three individual ensemble members and for the three-member ensemble mean.

only because of the roles of sea ice in the climate system, but also because of potentially important impacts of future changes of sea ice: new opportunities for navigation and offshore industry, changes in marine ecosystems, and changes in coastal erosion and perhaps Arctic storminess. A scenario working group appointed by ACIA identified five global climate models as sources

Box 1. Five global climate models.

Canadian Climate Centre for modeling and analysis (CCCma). See Flato et al. (2000)

Geophysical Fluid Dynamics Laboratory (GFDL). See Knutson et al. (1999)

European Centre/Hamburg (ECHAM), MaxPlanck-Institute. See Roeckner et al. (1999)

Hadley Centre for Climate Prediction and Research, Climate Model version 3 (HadCM3). See Gordon et al. (2000)

National Center for Atmospheric Research (NCAR), Climate System Model. See Boville et al. (2001) of information on projected changes in the Arctic climate system. These models, selected on the basis of documentation in the refereed literature and the availability of archived output, are listed in Box 1.

All five models have been used in greenhouse simulations employing the IPCC's B2 forcing scenario, which represents a more modest rate of increase of greenhouse gas concentrations than does its counterpart, the A2 scenario (IPCC 2000). The B2 scenario simulations generally begin in the mid-to-late 20th century with historical forcing, and then continue through 2100 with the B2 forcing. The CCCma model was used for three different simulations of the 1975-2100 period; the three ensemble members differ as a result of perturbations of the initial conditions. The archives of all the model simulations include monthly grids of sea ice coverage, in addition to monthly (and sometimes daily) grids of many other variables, including surface air temperature. The monthly output was used in the present evaluation. 
Fig. 2. Time series of (a) March and (b) September ice extents simulated by the five global climate models. The ice extents are unadjusted.
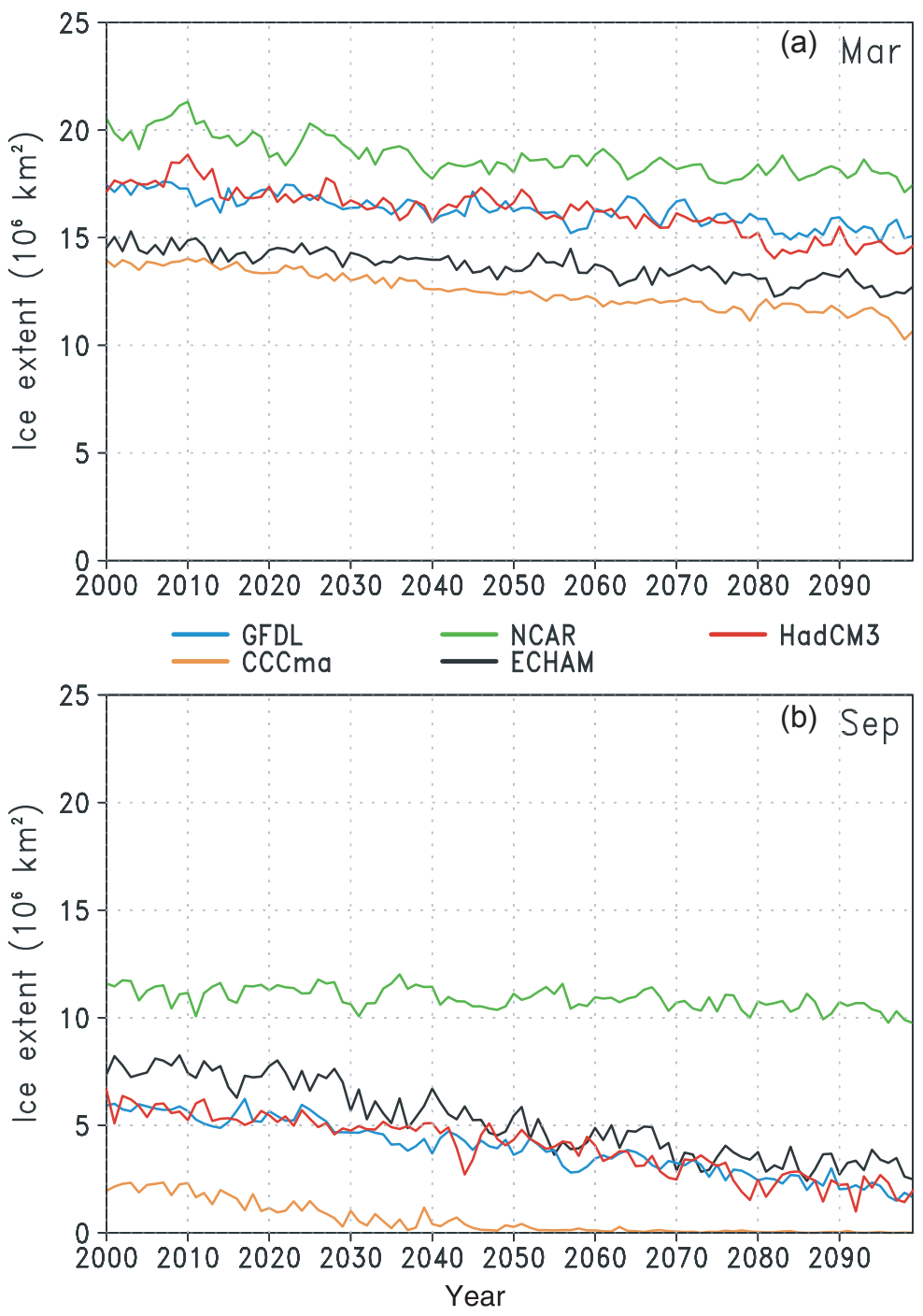

\section{Results}

All five models project increases in Arctic surface air temperature and decreases of Arctic sea ice coverage. Figure 1 shows the 21 st century time series from the various models, all in the form of 11-year running means, of the surface air temperature averaged over $60-90^{\circ} \mathrm{N}$. The warming by the end of the century ranges from approximately $3.5^{\circ} \mathrm{C}$ in the NCAR model to approximately $5.5^{\circ} \mathrm{C}$ in the ECHAM model. For comparison, the projected increases of global mean temperature range from about $1.2^{\circ} \mathrm{C}$ in the NCAR model to about $2.5^{\circ} \mathrm{C}$ in the ECHAM, HadCM3 and CCCma models. These global warmings are in the lower portion of the $1.5-4.5^{\circ} \mathrm{C}$ range in the IPCC's recent assessment (2001), confirming that the $\mathrm{B} 2$ scenario of forcing is less extreme than the less conservative scenarios such as A2.

Figure 1 also shows that the three members of the CCCma ensemble produced similar changes of Arctic temperature. In fact, the three CCCma time series are more similar to each other than to any of the other models' time series. This similarity of the three ensemble members was found in the simulations of other variables, including sea ice. Hence we present the CCCma sea ice results in the form of averages of the output from the three ensemble members, thereby homogenizing the display of the results. 


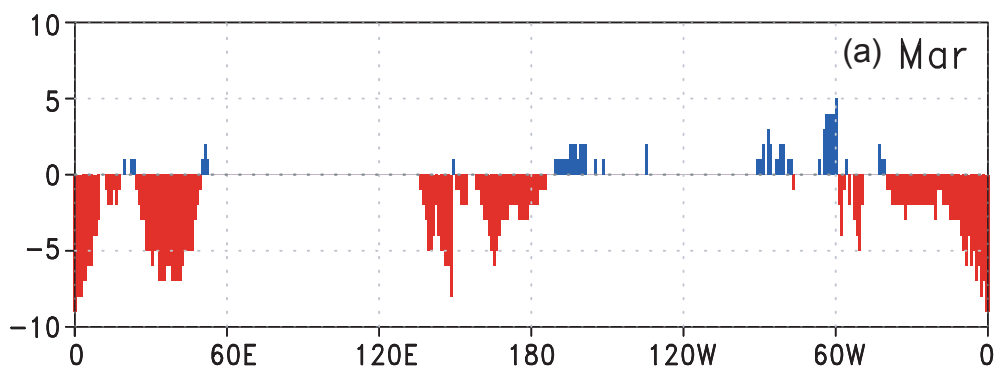

Fig. 3. Longitudinal distributions of the adjustments applied to ice extent simulated by the HadCM3 model in (a) March and (b) September. Negative (red) values denote removal of over-simulated ice; positive (blue) values denote addition of under-simulated ice.

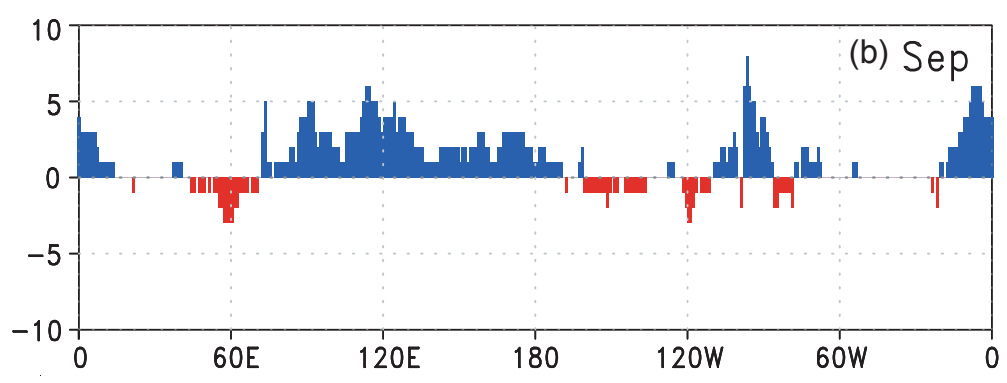

Figure 2 shows the time series of the simulated ice extent from each model for March and September, the calendar months of maximum and minimum sea ice extent in the Arctic. The general decrease of sea ice in the 21st century is common to the models, although interannual to decadal variations are superimposed on the decreases. However, an outstanding feature of Fig. 2 is the spread of the present-day simulations. Figure $2 \mathrm{a}$ shows that the simulated ice extent varies from 14 to 20 million $\mathrm{km}^{2}$ in March, and from 2 to nearly 12 million $\mathrm{km}^{2}$ in September. The corresponding observed ice extents, based on satellite passive microwave measurements, are approximately 16 and 8 million $\mathrm{km}^{2}$, respectively. The biases of the individual models are sufficiently large that they represent significant contaminations of the projections of sea ice cover throughout the $21 \mathrm{st}$ century. In some cases, the biases of the presentday extent are actually larger than the changes projected by the same models over the 20002100 period.

It should also be noted that the models' sensitivity to greenhouse forcing can be affected by the coverage of sea ice in the control (present-day) climate. For example, Spelman \& Manabe (1984) found that in control runs with excessive ice the additional ice available for melting enhances the feedback to a climate warming. In this way, the warming can be greater in a simulation with larger initial ice cover. However, the use of different models (as in this study) introduces other sensitivities that evidently outweigh the tendency found by Spelman \& Manabe in their different simulations with the same model.

Because the present-day biases are large, they can dominate estimates of ice extent based on the raw output of a particular model. If one is willing to assume that there is some useful information in the rates of change of the ice coverage in the model simulations - an assumption that is clearly open to question - then the model-derived estimates of future ice cover can be enhanced by adjustments for the biases in the initial (ca. 2000) simulated extents. In effect, this strategy superimposes the simulated variations and trends onto the "correct" initial state of each simulation of the 21st century. The implementation of this strategy is complicated somewhat by the fact that the models' systematic errors are larger in some regions than in others. Accordingly, the procedure followed here is an adjustment of each model's simulated ice extent on the basis of that model's bias of present-day (1980-1999) extent, relative to the corresponding observed extent, in each calendar month and at each longitude (in $1^{\circ}$ increments). The source of the observational data was the Hadley Centre's HadISST data set, version 1.1 (Rayner et al. 2000). The sea ice information in HadISST for the 19801999 period is based largely on satellite passive microwave measurements (Cavalieri et al. 1997). 
Fig. 4. Time series of (a) March and (b) September ice extents simulated by the five global climate models (Box 1) after adjustments for the present-day biases.
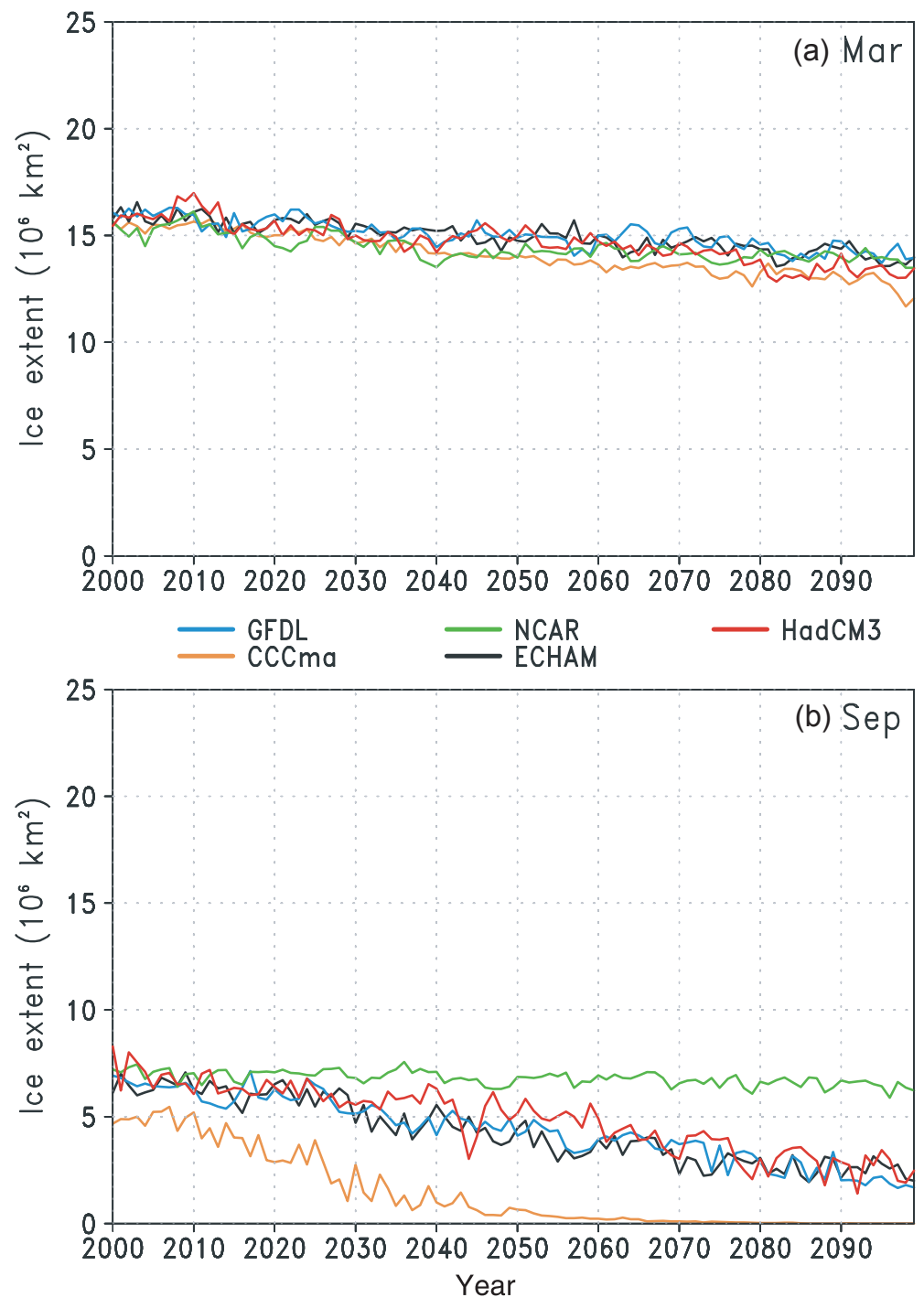

The adjustment procedure is essentially an addition or removal of sea ice at each longitude by an amount equivalent to the negative of the bias at the particular longitude and calendar month. This procedure is different from the so-called "flux adjustment" often employed in coupled global model simulations, since the procedure used here simply imposes a posteriori or ad hoc modifications of the model output; the model simulations are unaffected by the adjustments. As with flux adjustments, however, our procedure implicitly assumes that the optimal adjustments do not change with time - an assumption that is almost certainly subject to some error.

As an example of the adjustment of ice extent,

Fig. 3 shows the longitudinal dependence of the adjustment (in degrees of latitude) to HadCM3's sea ice in March and September. Where the model over-simulates sea ice, the adjustment is negative (red). Where the model under-simulates ice, the adjustment is positive (blue). It is apparent that HadCM3's bias is strongly dependent on longitude and season, although the bias is generally positive in March and negative in September. The adjustments at some longitudes exceed five degrees of latitude, as in the downward adjustment of the model's March ice extent in the eastern North Atlantic subpolar seas $\left(20^{\circ} \mathrm{W}-50^{\circ} \mathrm{E}\right)$.

Figure 4 shows the 21 st century time series of each model's adjusted ice extent for March 


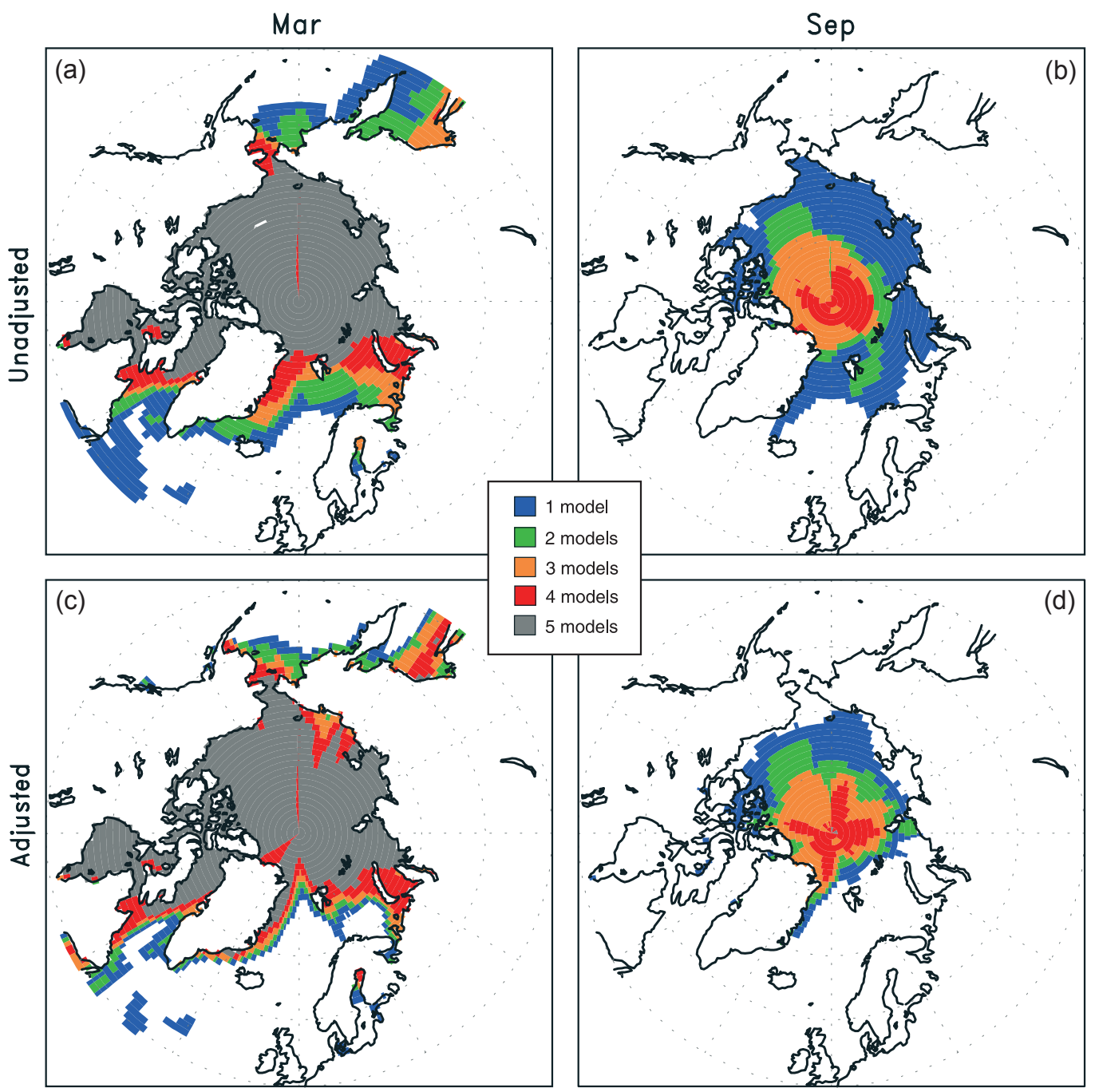

Fig. 5. Geographical distribution of the coverage of sea ice during March (a, c) and September (b, d) in the 2070-2090 time slice. The key shows colours which denote how many of the five models (Box 1) according to which sea ice is present. Upper panels are for unadjusted extents and lower panels are for adjusted extents.

and September. The adjusted time series show much less spread among themselves than do the unadjusted time series in Fig. 2, since the models now have a common "starting point". (Figure 4's extents in the year 2000 differ slightly because the adjustments are based on the means over 1980-1999, which are not exactly the same as the year 2000 values.)

While the March extents vary little among the models in the adjusted time series (Fig. 4a), the September extents (Fig. 4b) develop somewhat more spread by 2100 . The most ice is projected by the NCAR model, in which the present-day Arctic is coldest. The least ice in September is projected by the CCCma model, which simulates the warmest present-day climate of the Arctic. The CCCma model deserves special mention because its simulation became ice-free in September by approximately 2060 (Fig. 2b). This model's present-day bias was quite negative in September, so the positive adjustment effectively led to a constant (nonzero) ice cover beyond 2060. Our adjusted time series in Fig. $4 \mathrm{~b}$ is based on a continuation of the pre-2050 rate of decrease into 
the period beyond 2050, so the adjusted values erode at the same rate as the unadjusted iceleading to ice-free Septembers in CCCma by the 2070s.

The net changes of annual mean Northern Hemisphere sea ice are summarized in Table 1. The changes are presented as actual areal changes $\left(10^{6} \mathrm{~km}^{2}\right)$ and as percentage changes from the initial values of both the adjusted and unadjusted time series. The percentage changes vary from about $14 \%$ to $42 \%$ in the unadjusted time series, and from about $12 \%$ to $46 \%$ in the adjusted time series. These percentages would be smaller if they were based solely on the winter time series, and larger if based solely on summer values, as one may infer from Fig. 4.

Finally, Fig. 5 provides spatial distributions of the simulated sea ice by showing the number of models in which sea ice is present during 2080 2099 at each location in March and September in both the adjusted and unadjusted results. Figures $5 \mathrm{c}$ and $\mathrm{d}$ both show the narrowing of the spread achieved by the adjustment. Figure $5 \mathrm{c}$, in particular, shows that wintertime sea ice over the Arctic Ocean and various peripheral seas persists through the late 21st century in all models, at least according to the adjusted output of the B2 simulations. While these distributions say nothing about the ice thickness, they do indicate that the reductions of winter ice extent are quite modest in the B2 scenarios. The summer extents show greater inter-model variations and more substantial reductions (Figs. 5b, d). Large portions of the Arctic Ocean are ice-free in at least some of the models, even after adjustment (Fig. $5 d)$. One implication of Fig. $5 \mathrm{~d}$ is that navigational opportunities will be greatly increased in the Arctic Ocean during summer. Examination of the corresponding changes for other warmseason months would permit inferences about changes in open-water season length at various locations.

\section{Conclusion}

The following are the highlights of the results presented here:

- Projections of 21st century ice extent by coupled global models are strongly dependent on, if not dominated by, the models' simulations of present-day ice extent.

- Adjustments based on biases of the simulated present-day ice extent narrow the spread among the model projections, subject to the caveat that adjustments are strictly ad hoc, non-physical and open to question concerning the validity of the assumption of temporal invariance over the 100year time frame.

- The model with the most ice in its control climate has the smallest percentage loss (as well as the smallest absolute loss) of ice over the 21 st century; the model with the least ice in its control climate has the largest loss of ice by 2100 . However, this finding does not represent a general rule; for example, it is not valid if one compares the HadCM3 and ECHAM4 models (Table 1). In addition, it is counter to Spelman \& Manabe's (1984) results obtained from different simulations by the same model, indicating that various sensitivities affect the relationship between polar warming and initial sea ice extent.

- The models with the warmest (coldest) present-day Arctic climate show the largest (smallest) reductions of ice extent, even after the adjustments are imposed.

Despite the ad hoc nature of the adjustments applied here, the adjusted sea ice distributions should be more useful for applications such as the Arctic Climate Impact Assessment, which requires "best estimates" of the future distribution of sea ice. We believe that the adjusted ice extents, while still flawed, are more credible than the unadjusted estimates because one obvious source of error (biases in the initial state) have been addressed, albeit in a non-physical way. It

\begin{tabular}{|c|c|c|c|c|}
\hline Model & $\begin{array}{c}\text { change, } 10^{6} \mathrm{~km}^{2} \\
\text { (unadjusted) }\end{array}$ & $\begin{array}{c}\% \text { change } \\
\text { (unadjusted) }\end{array}$ & $\begin{array}{c}\text { change, } 10^{6} \mathrm{~km}^{2} \\
\text { (adjusted) }\end{array}$ & $\begin{array}{l}\% \text { change } \\
\text { (adjusted) }\end{array}$ \\
\hline CCCma & from 9.7 to 5.6 & $-42 \%$ & from 12.3 to 6.6 & $-46 \%$ \\
\hline ECHAM & from 11.9 to 8.9 & $-25 \%$ & from 12.3 to 9.3 & $-24 \%$ \\
\hline GFDL & from 11.9 to 8.5 & $-29 \%$ & from 12.3 to 8.6 & $-30 \%$ \\
\hline HadCM3 & from 12.8 to 9.4 & $-27 \%$ & from 12.3 to 9.1 & $-26 \%$ \\
\hline NCAR & from 16.5 to 14.2 & $-14 \%$ & from 12.3 to 10.8 & $-12 \%$ \\
\hline
\end{tabular}


should be noted that the procedure used here is not the only possible method for adjusting the simulated ice coverage; for example, one could perform sea ice simulations "off-line" using observed initial conditions for sea ice (e.g. the year 2000 distribution) and forcing from the atmospheric component of the climate model's simulation of the 21 st century.

As coupled climate models become more realistic, the magnitude of the required adjustments will almost certainly decrease. The adjustments are already relatively small in some of the models used here. However, biases and the potential for enhancement by adjustment are likely to persist on the regional scale for the foreseeable future, during which time assessment projects such as ACIA can benefit from enhancements of the projected sea ice distributions.

\section{References}

Boville, B. A., Kiehl, J. T., Rasch, P. J. \& Bryan, F. O. 2001: Improvements to the NCAR CSM-1 for transient climate simulations. J. Clim. 14, 164-179.

Cavalieri, D. J., Gloersen, P., Parkinson, C. L., Comiso, J. C. \& Zwally, H. J. 1997: Observed hemispheric asymmetry in global sea ice changes. Science 278, 1104-1106.
Flato, G., Boer, G. J., Lee, W. G., McFarlane, N. A., Ramsden, D., Reader, M. C. \& Weaver, A. J. 2000: The Canadian Centre for Climate Modelling and Analysis global coupled model and its climate. Clim. Dyn. 16, 451-468.

Gordon, C., Cooper, C., Senior, C. A., Banks, H. T., Gregory, J. M., Johns, T. C., Mitchell, J. F. B. \& Wood, R. A. 2000: The simulation of SST, sea ice extents and ocean heat transports in a version of the Hadley Centre coupled model without flux adjustments. Clim. Dyn. 16, 147-168.

IPCC (Intergovernmental Panel on Climate Change) 2000: Special report on emission scenarios: a special report of Working Group III of the Intergovernmental Panel on Climate Change. (N. J. Nakicenovic, J. Alcamo, G. Davis \& 25 others, eds.) Cambridge: Cambridge University Press.

IPCC (Intergovernmental Panel on Climate Change) 2001: Climate change 2001: the scientific basis. Contribution of Working Group I to the Third Assessment Report of the Intergovernmental Panel on Climate Change. (J. T. Houghton, Y. Ding, D. J. Griggs, M. Noguer, P. J. van der Linden, X. Dai, K. Maskell \& C. C. Johnson, eds.) Cambridge: Cambridge University Press.

Knutson, T. R., Delworth, T. L., Dixon, K. W. \& Stouffer, R. J. 1999: Model assessment of regional surface temperature trends (1949-1997). J. Geophys. Res. 104(D24), 3098130996.

Rayner, N. A., Parker, D. E., Frich, P., Horton, E. B., Folland, C. K. \& Alexander, L. V. 2000: SST and sea-ice fields for ERA40. In: Proceedings of the Second International Conference on Reanalysis. Wokefield Park, Reading, UK, 23 27 August 1999. WCRP 109, WMO/TD 985. Pp 18-21.

Roeckner, E., Bengtsson, L., Feichter, J., Lebeveld, J. \& Rodhe, H. 1999: Transient climate change simulations with a coupled atmosphere-ocean GCM including the tropospheric sulfur cycle. J. Clim. 12, 3004-3012.

Spelman, M. J. \& Manabe, S. 1984: Influence of oceanic heat transport upon the sensitivity of a model climate. $J$. Geophys. Res. 89(C1), 571-586. 